\title{
LEITURAS E RELEITURAS
}

Coordenador: João Alcxandre Barbosa

Participantes: Evelina Hoissel, Antonia Torreão Hernandez

e Frederico Barbosa.

\section{Descrição de atividades}

Inicialmente, o coordenador apresentou os participantes, as duas primeiras Professoras de Teoria Literária na Universidade Federal da Bahia e o terceiro Professor no Colégio Logos e no Anglo, de São Paulo, assim como procurou definir os objetivos da Mesa, isto é, uma discussão acerca da leitura de textos literários, em que, num primeiro momento, através da cxposição das duas professoras, se ouviria a leitura de textos sobre os scus trabalhos $\mathrm{cm}$ andamento visando o Doutoramento $\mathrm{c}, \mathrm{cm}$ seguida, uma exposição do professor Frederico sobre experiência com leitura no ensino secundário. Em seguida, o coordenador fez uma exposição sobre o tema em questão, discorrendo sobre a problemática da leitura e exemplificando com alguns textos. Cedendo a palavra à primcira expositora, a professora Evelina leu o texto sobre a leitura que $\mathrm{vem}$ fazendo das relações entre biografia e criação literária, tendo por base a obra de Guimarães Rosa, assim como documentos de ordem pessoal do escritor que servem para ir marcando a confluência de experiência $\mathrm{c}$ criação $\mathrm{cm}$ sua obra. No mesmo sentido, foi feita, em seguida, a exposição da professora Antonia que leu texto sobre o trabalho que vem realizando sobre as relações entre Ética c Literatura, tendo por fundamento uma leitura acurada de textos de Clarice Lispector. Finalmente, o professor Frederico relatou suas cxperiência de ensinamento de leitura de textos literários $\mathrm{cm}$ cscolas do segundo grau, fazendo questão de chamar a atenção para a cspecificidade deste tipo de Icitura no sentido de desmitificar funções que são impostas à própria litcratura.

Encerrando a Mesa, houve uma abcrtura às questõcs propostas pelos ouvintes e, em seguida, o coordenador fez um resumo das discussõcs, retomando trechos e completando a sua intervenção inicial.

Como os dois textos lidos pelas professoras da Universidade Federal da Bahia são capítulos de suas teses $\mathrm{cm}$ andamento, devendo, por isso, conservar o seu caráter inédito exigido para a defesa de título, c como a apresentação do 
professor Frederico, cmbora fundada cm apontamentos escritos, foi sobretudo oral. o que se publica, cm scguida, é o texto resultantc da participação do coordenador da Mesa-Redonda. 


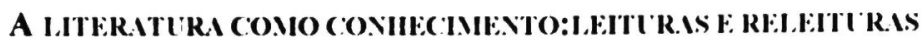

João Alcxandre Barbosa

Dentre as questð̋cs mais dificcis que ccrcam a tcoria litcrária cstá aqucla de indagar sobre a perenidade das obras literárias. Por que relcmos certas obras $\mathrm{c}$ por que estas obras sempre oferecem elementos novos à consideração? Obras como as de Dantc, de Shakespeare ou Cervantes suportam há sćculos as leituras as mais diferentes c, no cntanto, permanccem com núclcos de interesse inaltcrados, permitindo aos lcitores acréscimos, modificaçõcs, um númcro cada vez maior de aproximações diferentes. Por isso mesmo, pode-se dizer que são as mesmas desde que foram escritas c publicadas c. lodavia. são diversas: cada sćculo tere o scu Dante, o scu Shakespeare, o scu Cervantes scm que. cntrctanto, scjam autores inteiramente diferentes daqueles que foram lidos c apreciados por scus públicos imcdiatos.

De uma mancira geral, a tais obras, isto ć. a obras que atravessam as ćpocas com a marca intensa da novidade mas, ao mesmo tempo, intensamente marcadas pclas suas ćpocas de origem, chamamos de clássicas. não apcnas para indicar a posição de tais obras com relação a outras obras que se scguiram c são delas decorrência ou com clas dialogam. mas ainda para cslabelecer o grau de valor com referência à leitura ou à relcitura que delas venham a ser feitas. Neste sentido. a leitura de uma obra clássica ć. quase scmpre, uma relcitura daquilo que significa a litcratura para o presente cm que se situa o Icitor. Dizcndo de outra mancira, o lcitor lê o que cstá na obra c relê o que cstá cittre aqucla obra c toda a sua cxperĉncia de lcitura anterior.

Por outro lado, ć possível dizer que a lcitura atual, cnvolvendo o presente situado do Icitor mas instigando-o a renovar a sua cxpericencia de lcituras anteriores, ć necessariamentc uma descobcrta. quer dizer, um modo único, ao menos no momento $\mathrm{cm}$ que sc realiza, de ajustar, para aqucla lcitura cspecifica, o discernimento crítico para a obra que se busca agora absorver c tudo o que significa aprendizado anterior advindo da cxperência com a litcratura.

Scndo assim, os movimentos de lcitura c relcitura de certas obras. daquelas que são identificadas por traços de perenidade, já por si supõcm uII modo de conhecimento que, com freqücencia,ć caractcrizado como de crudição litcrária.

$\mathrm{Na}$ verdade, todo o fecundo traballo da filologia ou da critica tcilual, todo o cnorme esforço dos historiadores litcrários no eslabclecimento de datas. origens, filiações $\mathrm{c}$ influĉncias, dando às obras os scus lugares nas ditcrsas $c$ 
numerosas literaturas nacionais, revelando as inúmeras marcas do tempo nos textos escritos através de variantes, acréscimos c correções, tudo isso, por certo, faz parte de um conhecimento necessário para que as leituras e relcituras das obras possam, não apenas simplesmente serem realizadas, como ainda sirvam para testar mesmo a força de sua permanência por entre as vicissitudes da história c do tempo. Não é, entretanto, sobre este tipo de conhecimento, o tratamento do qual demandaria um tempo muito mais largo do que aquele de que agora dispomos, que quero fazer algumas reflexões.

O conhecimento de que quero tratar agora cstá. por um lado, articulado precisamente à questão com que comecci, quer dizer, a de saber se a perenidade atingida por certas obras ć decorrência de uma especificidade de conhecimcnto por clas vciculado c, por outro lado, de que modo o problema se coloca nas relações de leituras e releituras que envolvem tais obras. Ou, dizendo de um modo mais direto: cxiste uma forma de conhecimento própria da obra literária $\mathrm{c}$ que não se confunde com outras formas de conhecimento como aquelas das demais artes, ou da filosofia, ou das ciências, scjam as físico-matemáticas, sejam as naturais $\mathrm{c}$ biológicas? Ou, ainda mais simples: cxistc um conhecimento poćtico, se por poćtico for cntendido uma forma de articulação de linguagem, uma cspćcic de "linguagem dentro da linguagem", como queria o pocta c crítico Paul Valćry?

Antes da mais nada, no cntanto, ć preciso fazer uma adicrtência: quando sc fala $\mathrm{cm}$ conhecimento "que não se confunde" não sc quer apontar para a busca de um conhecimento autônomo, autotćlico, puro, desvinculado de todas as demais formas de cxpcrimentar a realidade através das quais são configurados os nossos discrsos campos de conhecimento. Não, o que se propõe ć pensar sc cxiste um conhecimento veiculado pela obra poćtica que, dependendo da intensidade de sua formulação, possa convirer $\mathrm{cm}$ pé de igualdade com as demais formas de conhecimento.

Por outro lado, ć preciso tambćm descartar, para início de conversa c para o nosso caso, os diversos usos possiveis que se tcm feito do poćtico para acrescentar clementos de conhecimento cm outras árcas, por onde sc costuma falar de funçõcs diversas do poćtico ou da litcratura, indo desde a sua utilização como documento histórico atć, por cxemplo,o scu uso como registro biográfico para lcituras psicanalíticas. Descartar tais usos ou funçõcs atribuidos ao poćtico não significa, todavia, csvaziá-lo de possívcis represcntaçõcs sociais, históricas ou psicológicas, mas tão somente não cdificar ali a sua validade como forma de conhecimento. Mesmo porque ć necessário, antes de tudo, comprecnder que o discurso poćtico, à diferença de outros tipos de discursos, é um discurso ficcional c que, portanto, a presença daquelas representações sempre ocorre transformada pela configuração ficcional do poćtico. O que significa afirmar que a validade do conhecimento veiculado pelo poćtico cstá antes no modo pelo 
qual foi possível articular os possíveis elementos de representação do que na pura e simples presença ou ausência desses mesmos clementos.

Nada melhor para a compreensão do que acaba de ser dito do que a lcitura de algumas páginas de prosa ou pocma $\mathrm{cm}$ que, verdadeiramente, ocorra a intensificação, pelo poético, de um ou outro daqueles elementos. Comecemos por uma página muito conhecida de Machado de Assis. É o capítulo CXXIII de Dom Casmurro, intitulado "Olhos de ressaca":

"Enfim, chegou a hora da encomendação e da partida. Sancha quis despedir-se do marido, e o desespero daquele lance consternou a todos. Muitos homens choravam também, as mulheres todas. Só Capitu, amparando a viúva, parecia vencer-se a si mesma.Consolava a outra, queria arrancá-la dali. A confusão era geral. No meio dela, Capitu olhou alguns instantes para o cadáver tão fixa, tão apaixonadamente fixa, que não admira the saltassem algumas lágrimas poucas e caladas...

As minhas cessaram logo. Fiquei a ver as dela; Capitu enxugou-as depressa, olhando a furto para a gente que estava na sala. Redobrou de caricias para a amiga, e quis levá-la; mas o cadóver parece que a retinha também. Momento houve em que os olhos de Capitu fitaram o defunto, quais os da viiva, sem o pranto nem palavras desta, mas grandes e abertos, como a vaga do mar lá fora, como se quisesse tragar também o nadador da manhã".

Quando lemos este capítulo, de um livro que termina no capítulo CXLVIII, já estamos quase fechando o volume: são as páginas do descnlace que se iniciam com a morte por afogamento de Escobar, as desconfianças do narrador Bentinho quc, com a scparação de Capitu $\mathrm{c}$ do filho, com o isolamento $\mathrm{c}$ as reflexões solitárias vai se transformando no Casmurro que assume a autoria do livro. Entretanto, a imagem mais forte do capítulo, aquela que lhe dá o título, "olhos de ressaca", embora não explicitada no texto c fonte de toda a desconfiança do narrador ["Momento houve em que os olhos de Capitu fitaram o defunto, quais os da viúva, sem o pranto nem palavras desta, mas grandes e abertos, como a vaga do mar lá fora, como se quisesse tragar também o nadador da manhã".], ć uma tradução, e tradução cstrutural porquc contextualizada, daquilo que está num dos capítulos iniciais do romance, o XXXII, também intitulado "Olhos de ressaca". Trata-se do encontro entrc o narrador e Capitu, ainda crianças, em que Bentinho vai encontrar a menina na sala dos pais, penteando os cabelos e pede-lhe para ver os olhos. Eis o trecho:

"Tinha-me lembrado a definição que José Dias dera deles, "olhos de cigana obliqua e dissimulada ".Eu não sabia o que era obliqua, mas dissimulada sabia, e queria ver se se podiam chamar assim. Capitu deixou-se fitar e examinar. Só me perguntava o que era, se nunca os vira; eu nada achei 
extraordinário; a cor e a doçura eram minhas conhecidas. A demora da contemplação creio que the deu outra idéia do men intento; imaginou que era um pretexto para mirá-los mais de perto, com os mens olhos longos, constantes, enfiados neles, e a isto atribuo que entrassem a ficar crescidos, crescidos e sombrios, com tal expressão que...

Retórica dos namorados, dá-me uma comparação exata e poética para dizer o que foram aqueles olhos de Capitu. Não me acode imagem capaz de dizer, sem quebra da dignidade do estilo, o que eles foram e me fizeram. Olhos de ressaca? V'á, de ressaca. É o que me dá idéia daquela feição nov'a. Traziam não sei que fluido misterioso e enérgico, uma força que arrastav'a para dentro, como a vaga que se retira da praia, nos dias de ressaca. Para não ser arrastado, agarrei-me às outras partes vizinhas, às orelhas, aos braços, aos cabelos espalhados pelos ombros; mas tão depressa buscav'a as pupilas; a onda que saia delas crescendo, cava e escura, ameaçando envolver-me, puxar-me e tragar-me".

Deste modo,toda a magistral intensidade narrativa do capítulo CXXIII, $\mathrm{cm}$ que a psicologia das cmoções $\mathrm{c}$ dos afetos encontra, para dizer com T.S.Eliot, o scu "corrclato objetivo" na imagem marinha, tradutora da morte de Escobar, interiorizada na percepção dos olhos de Capitu, somente é possibilitada pela leitura do intervalo entre os dois capítulos lidos c relidos.

Sendo assim, aquilo que o último capítulo oferece como conhecimento da psicologia do narrador ao lcitor ć mais do que um contcudo psicológico: os proccdimentos poćticos adotados pelo cscritor, cstabcleccndo precisas relaçõcs de imagem c sábias cscolhas vocabulares, que operam reverberaçõcs contínuas de significado, criam o espaço para a intensificação daquela função poćtica da linguagem. tal como definida por Roman Jakobson, quando, cntão, o que ć significado narrativo torna-se intciramente dependente da mais ampla articulação do texto.

Entre os olhos de Capitu c o cadáver de Escobar, a imagem marinha da ressaca ć também força de atração capaz de tragar, "como a vaga do mar lá fora", a imaginação do leitor. Dadas as reıcrberações c as dependências instauradas no espaço do texto, o conhecimento aprecndido pelo leitor ć de ordem psicológica mas ć mais do que isso. Como negar, por cxemplo, o fato de que ć por força da presença dos elementos marinhos contidos na imagem criada no capítulo XXXII, c depois traduzidos como mctáfora no capítulo postcrior. que o leitor, por assim dizer, conhece o ambiente, o mcio carioca $\mathrm{cm}$ que se passa o romance? Mais ainda: pela relcitura, ć possível perceber como o motivo da mortc por afogamento, entrclaçado ao do ciúme que corrói o narrador, já estava insinuado na caractcrização "de ressaca" dos olhos de Capitu, "oblíqua c dissimulada" nas artimanhas para fazcr Bentinho cscapar do scminário, do capítulo XXXII. 
Por tudo isso, o que se quer dizer é que o conhecimento veiculado pelo texto machadiano, assim como ocorre $\mathrm{cm}$ todos aqueles textos que suportam a relcitura c mcsmo a cxigem como condição fundamental de acréscimo. ć dependente da própria organização do discurso ficcional que dere ser percebida c procurada pelo leitor para que cle possa absoricr a especificidade daquele conhecimento. Não ć um conhecimento progressivo ou por acumulação: a sua possibilidade cstá na lcitura [que scmpre cxigc a relcitural de uma região de intervalo situada entre os contcudos de representação c sua cfetivação poética. vale dizer, sua instauração como "linguagem dentro da linguagem".

Por isso, um crítico nosso contcmporânco, o inglês Frank Kermodc. pôde chegar à conclusão de que "a sobrevivència do clássico deve depender dele possuir um acréscimo [surplus] de significante". E clc acrescenta: "as in King Lear or Iluthering Ileights this may expose them to the charge of confusion, for they must always signify more than is needed by any one interpreter or any one generation of interpreters". Ora, ć precisamentc a possibilidade dessa "charge of confusion "que responde pela perenidade da obra clássica, impondo-lhe relcituras sucessivas, sempre incompletas. Relcituras que, buscando absorver aquele "surplus"de significante referido por Kcrmode, terminam por ampliar o leque de significados que tradızcm o conhecimento veiculado pela obra. Não é possírcl, todavia, chegar a cstes scm haver passado por aquelc: cntre "cncantamento c cnigma", para usar os termos opcracionais de Northrop Frye. cm Spiritus Mundi, a relação termina por ser tão estrcita, uma ve\% rcalizada a obra, que a resposta ao "enigma" que a obra propõc, cujo encontro parece ser responsável pelo "encantamento", não ć sequer uma resposta. Ou, como diz o próprio Fryc, o cnigma da pocsia não ć o que solicita uma resposta fora do poema mas o que, dentro, ć o scu charme, mágica, cncantamento. Pode-se afirmar, assim, que aquilo que é conhecimento veiculado pela obra literária só se dá pela passagem, às vêzes penosa mas sempre compensadora, pelos caminhos da poćtica, quer dizer, pelos meios específicos de configuração ou reconfiguração lingüística dos clementos de representação que precnchem aquele conhecimento.

Nestc sentido, em ensaio muito recentc, o critico Peter Brooks, ccrerendo para a revista Critical Inquiry. cm scu número de Spring 1994, chamava a atenção para a necessidade de recuperar a Poćtica como disciplina dos cstudos literários e humanísticos, a fim de compensar aquilo que cle vê como hipertrofia da Estćtica c da Idcologia na Icitura mais recente da litcratura nos circulos universitários norte-americanos. Daí mesmo o título provocador do cnsaio, "Acsthetics and Idcology: What happened to Poctics?" Refcrindo-se aos cstudantes de litcratura, diz clc:

"O que é mais dificil para eles -e dai mais necessário- é diminuir o trabalho de interpretação, a tentativa de transformar o texto em algum outro discurso ou sistema, e considerá-lo como uma manifestação das convenções, restrições 
e possibilidades da literatura[...] Os estudantes precisam, em seu trabalho sobre literatura, encontrar um momento de poética -um momento no qual eles sejam forçados a perguntar não somente o que o texto significa mas também como ele significa, quais suas bases como sistema de signo proliferador de sentido e como nós, leitores, através da competência que adquirimos lendo outros textos, ativamos e desenvolvemos sistemas que nos permitem detectar ou criar significado, racionalizar e organizar significados em modos categóricos". Já no fim do ensaio, Brooks fará a defesa completa de um retorno à Poética, afirmando que "a poética, como o estudo dos sistemas de produção de significado, oferece a melhor abordagem inicial à estética, pois permite ao leitor, ao critico ou estudante compreender antes de julgar e antes de fazer uma intervenção ideológica prematura". Sendo assim, é possivel chegar ao que scja conhecimento genuino veiculado pela literatura. Antes, Brooks mencionara a leitura de outros textos como fundamental para uma competência indispensável capaz de permitir o acesso à tradição $\mathrm{e}$, portanto, a outras vozes com as quais o leitor dialoga. Agora, já na conclusão de scu ensaio, é mais explícito:

"[...]os professores de literatura -de humanidades em geral- não têm escolha senão trabalharem dentro de tradições herdadas desde que a noção de tradição é absolutamente central para qualquer trabalho humanistico e mesmo umas das caracteristicas definidoras que colocam as humanidades à parte das ciências naturais e mesmo sociais.As humanidades são destinadas à preservação e transmissão de textos e artefatos do passado. A erudição universitária nas humanidades não podem se libertar da tradição sem se tornarem autistas. Ensinar humanidades significa fazer submergir a personalidade individual em algo mais amplo, em uma tradição cultural através da qual se fala e que se permite que fale através da própria pessoa. $O$ humanista é sempre um pouco como o que Keats, em sua famosa definição de 'capacidade negativa', chama de 'poeta camaleão'. O 'Personagem poético', diz Keats, não tem ell próprio -é tudo e nada-. Não tem caráter... O que choca o filósofo virtuoso, faz a delicia do Poeta camaleão... Um Poeta é a coisa mais apoética da existência; ele não tem Identidade -está contimuamente buscandoe ocupando algum outro Corpo"'. Kcats foi cocrentc: $\mathrm{cm}$ scu túmulo crigido no velho Cemitério Protestante de Roma, onde morreu, fez inscrever na lápide simples as palavras "aqui jaz AlguémlCujo Nome foi escritolna Água". Não antes, no cntanto, de escrever, em 1819, a admirável Ode sobre uma Urna Grega, cm que o pocta, aos 23 anos, conversa com a tradição cultural $\mathrm{cm}$ pleno Romantismo Inglês dos Oitocentos, não apenas pcla utilização de uma forma lírica de fortc acentuação Anacreôntica c Horaciana, mas fazendo da arte, de sua artc, a poćtica, um modo de representar uma outra arte, neste caso a da estatuária narrativa grega, fazendo da imagem da pocsia um veículo de conhecimento histórico. [Não posso deixar de lembrar aqui o livro reçente c magistral de Francis Haskell, History and Its Image. Art and the interpretation 
Barbosa, J.A., coord.

of the past. Newv Haven: Yale University Press, 1993, cm que a interpretação do passado, tarefa fundante da História, é pensada não apcnas $\mathrm{cm}$ tcrmos de documentos escritos, como quase sempre acontece, mas ainda $\mathrm{cm}$ termos das imagens impressas pela Arte nos artefatos humanos].

Engana-se, no cntanto, quem buscar na Ode de Keats a cxatidão do conhecimento histórico, ainda que seja a precisão com que o pocta soube fixar a paisagem grega de extrema delicadeza arcádica $c$ as narrativas míticas ali cnvolvidas, pois, "cameleônico", como cle mesmo queria, o objeto histórico que cle viu e agora procura traduzir não é scnão um corrclato objctivo, segundo os termos de T.S.Eliot, com que opera a tradução, cm linguagem de pocma, daquela linguagem mais intima dos sentimentos pessoais, emoçõcs $c$ pensamentos que, num momento, articularam a sua identidade estilhaçada $\mathrm{cm}$ busca da sutura entre beleza c verdade, como dirá nos últimos versos célebres da Ode, cuja cstrofe cito na tradução magistral de Augusto de Campos:

"Ática forma! Altivo portc! cm tua trama

Homens de mármore e nutheres cmolduras

Com galhos de floresta e palmilhada grama:

$\mathrm{Tu}$, forma silenciosa, a mente nos torturas

Tal como a eternidade: Fria Pastoral!

Quando a idade apagar toda a atual grandeza,

Tu ficarás, em meio às dores dos demais, Amiga, a redizer o dístico imortal:

"A beleza ć a verdade, a verdade a belcza"

É tudo o quc há para sabcr, c nada mais". 